\title{
Ablation of TRPV1 + Afferent Terminals by Capsaicin Mediates Long-Lasting Analgesia for Trigeminal Neuropathic Pain
}

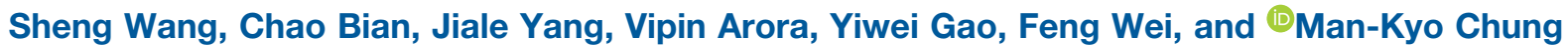

https://doi.org/10.1523/ENEURO.0118-20.2020

Department of Neural and Pain Sciences, School of Dentistry, University of Maryland, Program in Neuroscience, Center to Advance Chronic Pain Research, Baltimore, MD 21201

\begin{abstract}
Trigeminal neuropathic pain (TNP) is often resistant to current pharmacotherapy, and there is a pressing need to develop more efficacious treatments. Capsaicin is a pungent ingredient of chili peppers and specifically activates transient receptor potential vanilloid subtype 1 (TRPV1), a $\mathrm{Ca}^{2+}$-permeable ion channel. Topical capsaicin invariably induces burning pain. Paradoxically, the transient pain is often followed by prolonged attenuation of the preexisting pathologic pain from the same region. However, the mechanisms underlying capsaicin-induced analgesia are not well understood. Although the reports of the involvement of TRPV1 and TRPV1 + afferents in neuropathic pain are controversial, we recently demonstrated that TRPV1 and TRPV1+ afferents are involved in mechanical hyperalgesia in mice with chronic constriction injury of the infraorbital nerve (ION-CCl). Consistently, chemogenetic inhibition of TRPV1-lineage (TRPV1-LN) afferents attenuated mechanical hyperalgesia and ongoing pain. In mice with ION-CCI, we found that a single focal injection of capsaicin into facial skin led to attenuation of mechanical hyperalgesia over two weeks. Capsaicin treatment also attenuated secondary hyperalgesia in extraterritorial mandibular skin. Furthermore, capsaicin treatment decreased ongoing pain. Longitudinal in vivo two-photon imaging of cutaneous nerve fibers showed that such capsaicin-induced analgesia is correlated with cutaneous nerve terminal density. Furthermore, preventing capsaicin-induced ablation of afferent terminals by co-administration of capsaicin with MDL28170, an inhibitor of calpain, abolished capsaicin-induced analgesia. These results suggest that a single focal injection of capsaicin induces long-lasting analgesia for neuropathic pain via selective ablation of TRPV1+ afferent terminals and that TRPV1 + afferents contribute to the maintenance of TNP.
\end{abstract}

Key words: analgesia; capsaicin; neuropathic pain; orofacial pain; TRPV1

\section{Significance Statement}

Capsaicin has long been used as an analgesic to treat chronic pain conditions. Topical capsaicin is an FDAapproved treatment for neuropathic pain. However, the mechanisms underlying capsaicin-induced analgesia have been enigmatic for centuries. Despite evidence for clinical analgesia, data supporting the analgesic effects of capsaicin on neuropathic pain in preclinical model is rare. We found that a single focal injection of capsaicin to facial skin robustly attenuated trigeminal neuropathic pain (TNP) in mice for longer than two weeks, which is mediated by localized ablation of transient receptor potential vanilloid subtype 1 (TRPV1)+ terminals in the skin. These results suggest that TRPV1+ afferents contribute to the maintenance of TNP and that capsaicin injection could be a safe and effective treatment for TNP.

Received March 27, 2020; accepted May 7, 2020; First published May 13, 2020.

The authors declare no competing financial interests.
Author contributions: S.W., C.B., J.Y., F.W., and M.-K.C. designed research; S.W., C.B., J.Y., V.A., and Y.G. performed research; S.W., C.B., J.Y., V.A., Y.G., F.W., and M.-K.C. analyzed data; C.B., F.W., and M.-K.C. wrote the paper. 


\section{Introduction}

Trigeminal nerve damage due to accidents, orthognathic surgery, or dental procedures often causes trigeminal neuropathic pain (TNP), which becomes chronic, lasting more than a year, in one third of patients (Agbaje et al., 2016). Since TNP responds more poorly to conventional medications than does spinal traumatic neuropathic pain (McQuay et al., 1996; Haviv et al., 2014), development of novel methods to manage TNP is crucial.

Transient receptor potential vanilloid subtype 1 (TRPV1) is a pro-nociceptive ion channel protein activated by capsaicin, heat and multiple endogenous ligands (Chung et al., 2011). Interestingly, administration of capsaicin not only produces transient burning pain but also induces analgesia for neuropathic pain conditions (Szallasi and Blumberg, 1999; Chung and Campbell, 2016). Topical capsaicin relieves self-reported pain ratings by $>30 \%$ for approximately three months in $\sim 40-45 \%$ of postherpetic neuralgia patients (Mou et al., 2013; Treede et al., 2013). Topical capsaicin not only attenuates pain aversion but is also reported to attenuate mechanical hyperalgesia in patients with peripheral neuropathy from multiple etiologies (Kennedy et al., 2010; Zis et al., 2014). The therapeutic effects of topical capsaicin on dynamic allodynia are even greater than those of pregabalin (Cruccu et al., 2018). Thus, targeting TRPV1 + afferents using topical capsaicin is a promising approach to treating neuropathic pain, especially in patients whose hyperalgesia is likely maintained by sensitized nociceptors (Baron et al., 2017). In addition to topical application, intraarticular or intrathecal injection of capsaicin or resiniferatoxin (RTX), a potent TRPV1 agonist, is also under active development for treating chronic pain (ladarola et al., 2018; Sapio et al., 2018; Stevens et al., 2019).

Despite clear therapeutic benefits of capsaicin, roles of TRPV1 and TRPV1+ nociceptors in neuropathic pain are controversial, and therefore, the logical rationale for capsaicin therapy is not well supported by mechanistic insights. A majority of reports dispute the involvement of these entities in neuropathic mechanical allodynia: knock-out or knockdown of TRPV1 does not affect mechanical hyperalgesia following peripheral neuropathy in mice (Caterina et al., 2000; Hirai et al., 2014). Genetic ablation of TRPV1+ neurons or chemical ablation or desensitization of TRPV1+ afferents neither prevented nor attenuated mechanical hyperalgesia following neuropathy (Ossipov et al., 1999; King et al., 2011; Mishra et al., 2011; Abooj et al., 2016). These data contrast sharply with the aforementioned clinical data, as well as with

This work was supported by National Institutes of Health Grants DE023846 (to M.-K.C.) and DE027731 (to M.-K.C. and F.W.).

Acknowledgements: We thank Dr. James Campbell in Centrexion Therapeutics Corporation for providing injectable capsaicin and Dr. Michael Caterina for helpful comments.

Correspondence should be addressed to Man-Kyo Chung at mchung@ umaryland.edu.

https://doi.org/10.1523/ENEURO.0118-20.2020

Copyright @ 2020 Wang et al.

This is an open-access article distributed under the terms of the Creative Commons Attribution 4.0 International license, which permits unrestricted use, distribution and reproduction in any medium provided that the original work is properly attributed. multiple preclinical studies implicating TRPV1 and TRPV1+ afferents in mechanical hyperalgesia following neuropathy (Pomonis et al., 2003; Rashid et al., 2003; Kanai et al., 2005; Christoph et al., 2007; Watabiki et al., 2011). Our recent study showed that TRPV1 and TRPV1+ afferents are clearly involved in orofacial mechanical hyperalgesia following chronic constriction injury of infraorbital nerve (ION-CCI) in mice (Kim et al., 2014). Injection of TRPV1 antagonist into the trigeminal subnucleus caudalis (Vc) effectively attenuated mechanical hyperalgesia, while systemic treatment with RTX prevented development of mechanical hyperalgesia following ION-CCl. However, it is not known whether peripheral administration of capsaicin reduces trigeminal hyperalgesia in animals with $\mathrm{ION}-\mathrm{CCl}$.

Capsaicin-induced long-lasting analgesia in patients might occur through multiple mechanisms (Chung and Campbell, 2016). A dominant presumption is that analgesia produced by local administration of capsaicin is associated with the localized ablation of TRPV1+ peripheral fibers based on the observations that topical or intradermal injection of capsaicin denervates intraepidermal nerve fibers in humans (Simone et al., 1998; Malmberg et al., 2004; Anand and Bley, 2011). However, causal contribution of capsaicin-induced ablation of TRPV1 + nerve terminals to the analgesic effects on neuropathic pain has not been investigated. It appears to be straightforward that ablation of peripheral nociceptive fibers produces analgesia. However, considering the fact that multiple neuropathic pain conditions are accompanied by reductions in intraepidermal nerve fiber density (Landowski et al., 2016), it is important to determine the causal role for capsaicin-induced ablation of TRPV1 + fibers in capsaicin-induced analgesic effects. We recently showed that capsaicin ablates TRPV1+ nerve terminals through TRPV1-mediated $\mathrm{Ca}^{2+}$ influx followed by the activation of calpains, which are $\mathrm{Ca}^{2+}$-dependent proteases (Wang et al., 2017b). MDL28170, an inhibitor of calpains, reduced capsaicin-induced ablation of TRPV1+ afferent terminals in vitro and in vivo. Importantly, MDL28170 prevented capsaicin-induced thermal hypoalgesia in hindpaw (Wang et al., 2017b). However, it is not known whether such capsaicin-induced calpain-dependent ablation of TRPV1+ nerve terminals is necessary for analgesia of neuropathic pain conditions.

In this study, we tested the efficacy of focal injection of capsaicin in a mouse model of TNP and tested the hypothesis that TRPV1 + afferents contribute to the maintenance of TNP and capsaicin-induced ablation of peripheral nociceptive fibers is necessary for capsaicininduced long-lasting analgesia.

\section{Materials and Methods}

\section{Animals}

C57bl/6J (Jax \#00064), TRPV1 ${ }^{\text {Cre }}$ (Jax \#017769;

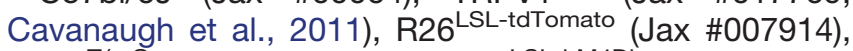
R26 $6^{\mathrm{mT} / \mathrm{mG}}$ (Jax \#007576), and R26 $6^{\mathrm{LSL}-\mathrm{hM} 4 \mathrm{Di}}$ (Jax \#026219) mice were purchased from The Jackson Laboratory. TRPV1 ${ }^{\text {Cre }}$ mice (Cavanaugh et al., 2011) express Cre recombinase under the control of TRPV1 promoter and, 
when crossed with a Cre-dependent reporter line, show labeling of afferents that have expressed TRPV1 at any stage of development (TRPV1-lineage; TRPV1-LN). Of these TRPV1-LN neurons, about half express TRPV1 in adult sensory ganglia (Cavanaugh et al., 2011). We generated a mouse line expressing tdTomato in TRPV1-LN neurons (TRPV $1^{\text {tdTomato }}$ ) by crossing TRPV $1^{\text {Cre }}$ mice and R26 ${ }^{\text {LSL-tdTomato }}$ mice. A mouse line expressing membrane-bound GFP (mGFP) from TRPV1 locus (TRPV $1^{\text {mGFP }}$ ) was generated by crossing TRPV $1^{\text {Cre }}$ mice and $R 26^{\mathrm{mT} / \mathrm{mG}}$ mice. A mouse line expressing inhibitory designer receptor exclusively activated by designer drugs (DREADD) under control of the TRPV1 promoter (TRPV1 ${ }^{\mathrm{hM} 4 \mathrm{Di}}$ ) was generated by crossing $\mathrm{TRPV}_{1}{ }^{\mathrm{Cre}}$ mice and R26 $6^{\mathrm{LSL}-\mathrm{hM} 4 \mathrm{Di}}$ mice. All procedures were conducted in accordance with the National Institutes of Health Guide for the Care and Use of Laboratory Animals and were performed under protocols approved by The University of Maryland Animal Care and Use Committees. Adult (eight-week-old) male and female mice were used for the experiments. Animals were group-housed under standard conditions with ad libitum access to water and food.

\section{TNP model}

To produce the TNP model, we performed chronic constriction injury of the infraorbital nerve (ION-CCl; Kim et al., 2014). Loose ligatures of the unilateral infraorbital nerve were done via an intraoral approach to keep orofacial skin intact for measurement of mechanical sensitivity. Mice were anesthetized with intraperitoneal injection of mixed ketamine $(100 \mathrm{mg} / \mathrm{kg})$ and xylazine $(10 \mathrm{mg} / \mathrm{kg})$. The head of the mouse was positioned in lateral recumbency and four limbs fixed on the table with adhesive tape. A 5to $7-\mathrm{mm}$-long incision was made along the gingivobuccal margin in the buccal mucosa, beginning immediately next to the first molar. The ION was freed from surrounding connective tissues by a glass rod and clearly visualized using a surgical microscope. At 3-4 $\mathrm{mm}$ from the nerve where its branches emerge from the infraorbital fissure, the ION was loosely tied with two chromic gut (4.0) ligatures, $2 \mathrm{~mm}$ apart. The incision was closed using veterinary tissue glue. The sham-operated mice received only a unilateral nerve exposure without ligatures.

\section{Behavioral assay for mechanical sensitivity}

All behavioral tests were conducted under blind conditions. To reduce any effects of restraint, the mouse was habituated for $20 \mathrm{~min} / \mathrm{d}$ for $3 \mathrm{~d}$ to stand on or lean against a regular leather work hand glove worn by the experimenter. As previously described (Kim et al., 2014), a series of calibrated von Frey (VF) filaments with bending forces ranging from 0.008 to $4 \mathrm{~g}$ were applied to the orofacial skin. For assessing primary or secondary hyperalgesia, these filaments were applied to the skin just behind the vibrissa pad within the infraorbital territory (V2) and the skin just below the ear within the mandibular nerve territory (V3), respectively. A brisk or active withdrawal of the head from the probing filament was defined as a nocifensive response. Each VF filament was applied five times at intervals of a few seconds. The response frequencies [(number of responses/number of stimuli) $x$ $100 \%$ ] to a range of VF filament forces were determined and S-R curves were plotted. Mechanical threshold was measured as the lowest intensity at which animals escaped from the stimuli over $50 \%$ of chance. In this mouse ION-CCI model, stable and long-lasting mechanical hyperalgesia and allodynia develops in maxillary V2 skin as well as in extraterritorial mandibular V3 skin within one week and persists over three months (Kim et al., 2014).

\section{Capsaicin injection into facial skin}

To determine the effects of focal capsaicin on mechanical hyperalgesia, capsaicin was injected at day 14 following ION-CCI. A single bolus of either vehicle $(20 \mu \mathrm{l}, 25 \%$ PEG300 in water) or capsaicin ( $10 \mu \mathrm{g}$ in $20 \mu \mathrm{l}$ of vehicle) was subcutaneously injected into the skin just behind the vibrissa pad, in which VF testing was performed for primary hyperalgesia. VF testing was performed up to four weeks except in a cohort that was tested up to nine weeks for determining the effects of two times of capsaicin injection.

\section{Intra-Vc microinjection of drug}

Microinjection into the Vc was performed as described previously (Kim et al., 2014; Wang et al., 2017a). Animals were anesthetized by intraperitoneal injection of ketamine and xylazine cocktail and placed in a Kopf stereotaxic apparatus. After a midline incision, an opening was made in the skull. The needle of a $0.5-\mu$ l Hamilton microsyringe was placed in the left or right $V_{c}$ regions according to the stereotaxic coordinates of the mouse brain $(7.80 \mathrm{~mm}$ anterior and $4.3 \mathrm{~mm}$ ventral to bregma and $\pm 1.60 \mathrm{~mm}$ lateral to the midline; Paxinos and Franklin, 2008). Clozapine Noxide (CNO; $0.1 \mu \mathrm{g} / 1 \mu \mathrm{l})$ or $2 \%$ lidocaine $(0.5 \mu \mathrm{l})$ was administered for $1 \mathrm{~min}$. Following injection, the needle was held in the tissue for $2 \mathrm{~min}$ to allow diffusion before removal.

\section{Conditioned place preference (CPP) assay}

To test effects of focal capsaicin treatment on $\mathrm{CCl}$-induced pain aversion, conditional preference place (CPP) was performed as previously described (Wang et al., 2018). Mice with ION-CCI or sham surgery were conditioned by intra- $V_{c}$ injection of $2 \%$ lidocaine or vehicle with capsaicin or saline pretreatment. In another experiment using TRPV $1^{\text {hM }}{ }^{4 \mathrm{Di}}$ and TRPV ${ }^{\text {Cre }}$ mice, $\mathrm{CNO}$ or vehicle was injected for conditioning. The CPP apparatus consisted of a rectangular chamber with one side compartment measuring $23 \times 26 \mathrm{~cm}$ with black walls and grids on the floor, a central compartment measuring $23 \times 11 \mathrm{~cm}$ with clear Plexiglas walls and a Plexiglas floor, and another side compartment measuring $23 \times 26 \mathrm{~cm}$ with white walls and a mesh metal floor. Mouse position during each day of testing was monitored. All mice were exposed to the environment with full access to all chambers for 30 min each day for days $1-3$. On day 3 , behavior was 
recorded for $15 \mathrm{~min}$ and analyzed to verify absence of preconditioning chamber preference. Following the preconditioning phase, mice underwent conditioning for 1-d trial with alternate treatment-chamber pairings at day 4 . Mice received vehicle and paired with a chamber in the morning. In the afternoon, drugs such as lidocaine or CNO were administered and paired with the other chamber. Mice were placed in the paired chamber with no access to the other chamber at 30 min after intra-Vc injection of vehicle or drugs, by which time animals had completely recovered from anesthesia by isoflurane. Drug and chamber pairing were counterbalanced. On day 5, mice were placed into the central chamber with access to all chambers. For $15 \mathrm{~min}$, with the mouse in a drug-free state, time spent in each of the chambers was recorded. Increased time spent in a chamber indicates preference for that chamber.

\section{Fluorescence imaging of cutaneous afferents in vivo}

Imaging was performed in the dark without any stimuli. After anesthetized with ketamine $(100 \mathrm{mg} / \mathrm{kg}$, i.p.) and $x y-$ lazine $\left(10 \mathrm{mg} / \mathrm{kg}\right.$, i.p.), adult TRPV $1^{\text {tdTomato }}$ or TRPV ${ }^{\mathrm{mGFP}}$ mice were placed prone on the animal platform with an electrical heating pad automatically around $38^{\circ} \mathrm{C}$. A hindpaw was extended and mounted on the platform. The glabrous flat skin was located at the mid plantar region behind the footpad between the secondary and third digits of the hindpaw. Saline was dropped on the mid plantar region and covered with a coverslip, and then a water immersion fluorescence objective was lowered into distilled water on the coverslip. TRPV1-LN afferent terminals expressing tdTomato or mGFP within the epidermis and dermis were imaged using a two-photon microscope (Scientifica) with a Ti:Sapphire laser (Mai Tai; Spectra Physics) using a Nikon X16 water-immersion lens (0.8 NA; $3.0 \mathrm{~mm}$ WD). The laser wavelength for two-photon excitation was $1040 \mathrm{~nm}$ for tdTomato and $900 \mathrm{~nm}$ for GFP, and the laser power was maintained at $\leq 25 \mathrm{~mW}$. Consecutive $z$-stack images were captured at $2-\mu \mathrm{m}$ (TRPV ${ }^{\text {tdTomato }}$ mice) or $0.5-\mu \mathrm{m}$ (TRPV1 ${ }^{\text {mGFP }}$ mice) depth intervals from the selected skin spots by using photomultiplier tubes in whole-field detection mode until the fluorescence signal became undetectable. $X Z$-axis orthogonal view of the skin was reconstructed using "volume viewer" plugins in ImageJ $(\mathrm{NIH})$. The raw images were processed to remove the nonspecific autofluorescence in the skin. To simplify the measurement procedure, the $Z$ projection was applied to a stack of all imaging sections and a single merged imaging of the skin spot was created. With ImagingJ analysis, a threshold was set to completely eliminate the background grayscale and binary images were generated. GFP + area and entire region of interest (ROI) area were measured, and the ratio of the GFP+ area/ROI area was calculated.

\section{Drugs}

Facial skin was injected with either vehicle $(20 \mu \mathrm{l}, 25 \%$ PEG300, and $\left.75 \% \mathrm{H}_{2} \mathrm{O}\right)$ or capsaicin $(10 \mu \mathrm{g}$ in $20 \mu \mathrm{l}$ of vehicle). Pharmaceutical grade of capsaicin dissolved in
PEG300 was kindly donated by the Centrexion Therapeutics Corporation. MDL28170 was from Tocris or Sigma. All other chemicals and drugs were purchased from Sigma-Aldrich. To determine the role of calpain, we injected $20 \mu \mathrm{l}$ of $10 \mathrm{~mm}$ MDL28170 (200 nmol), which effectively prevented the ablation of TRPV1 + afferents in hindpaw (Wang et al., 2017b).

\section{Design and statistical analysis}

The method of statistical analysis used in each dataset is indicated in the figure legends. Data from two groups were compared using Student's $t$ test. Data from three or more groups were compared using one-way ANOVA followed by Bonferroni post hoc test. The effects of pharmacological manipulations at different time points were analyzed with two-way ANOVA with repeated measures (RM). All multiple group comparisons were performed by Bonferroni post hoc test. Data are presented as mean \pm SEM. The criterion for statistical significance was $p<0.05$. All statistical analyses were performed using GraphPad Prism 6.0.

\section{Results}

\section{Chemogenetic inhibition of TRPV1-LN afferents attenuates TNP in mice with ION-CCI}

Our previous study suggested that TRPV1 in the central terminals of primary afferents in the Vc and TRPV1+ afferents mediates orofacial mechanical hyperalgesia following ION-CCl (Kim et al., 2014). To further determine the role of TRPV1 + afferents in mechanical hyperalgesia in mice with $\mathrm{ION}-\mathrm{CCl}$, we performed the chemogenetic inhibition using TRPV $1^{\mathrm{hM} 4 \mathrm{Di}}$ mice, which was produced by crossing TRPV1 ${ }^{\text {Cre }}$ with Rosa26 ${ }^{\text {LSL-hM4Di }}$ mice (Fig. 1A). Basal mechanical sensitivity and $\mathrm{ION}-\mathrm{CCl}$-induced mechanical hyperalgesia were comparable in TRPV $1^{\text {hM4Di }}$ and TRPV ${ }^{\text {Cre }}$ animals. However, mechanical hyperalgesia was significantly suppressed by intraperitoneal administration of CNO in TRPV1 ${ }^{\mathrm{hM} 4 \mathrm{Di}}$, an effect fully reversible after $1 \mathrm{~d}$. To examine whether functional blockade of TRPV1-LN peripheral nerve terminals mediates CNO-induced analgesia, we locally injected CNO into the ipsilateral facial skin in the same animals, and found that CNO also significantly attenuated mechanical hyperalgesia. In contrast, the contralateral injection of CNO did not affect mechanical hyperalgesia, suggesting that the action of $\mathrm{CNO}$ was local and peripherally confined. Intra-Vc injection of CNO also significantly attenuated mechanical hyperalgesia, which supports our previous observation that central terminals of TRPV1 + afferent are involved in mechanical hyperalgesia (Kim et al., 2014). Administration of CNO via any route did not affect mechanical sensitivity in sham groups either in TRPV $1^{\mathrm{hM} 4 \mathrm{Di}}$ or TRPV ${ }^{\text {Cre }}$ mice (data not shown). These results provide evidence that TRPV1$\mathrm{LN}$ afferents contribute to mechanical hyperalgesia following ION-CCl. Moreover, silencing central terminals of TRPV1-LN afferents within Vc promoted CPP in TRPV $1^{\text {hM4Di }}$ mice with ION-CCI but not in TRPV $1^{\text {Cre }}$ mice $\left(F_{(3,41)}=5.62, p=0.002\right.$; Fig. $\left.1 B\right)$, which further supports 

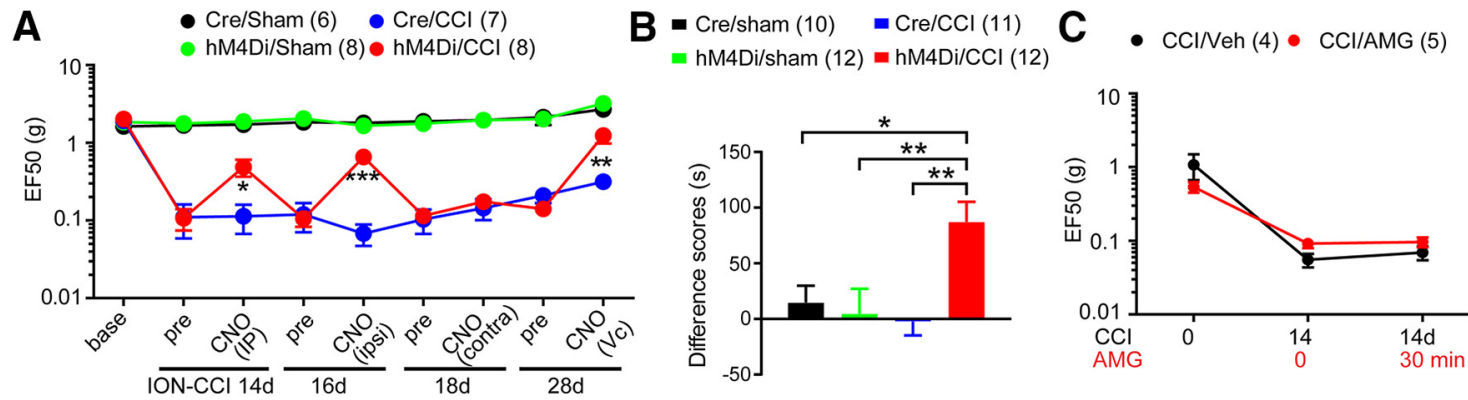

Figure 1. Chemogenetic inhibition of TRPV1 + afferent terminals attenuates mechanical hyperalgesia and ongoing pain in mice with ION-CCI. $\boldsymbol{A}$, Effects of $\mathrm{CNO}$ on mechanical hyperalgesia following ION-CCl in mice expressing inhibitory DREADD in TRPV1-LN neurons (TRPV1 ${ }^{\mathrm{Cre}} ; \mathrm{R}_{2} 6^{\mathrm{LSL}-\mathrm{hM} 4 \mathrm{Di}}$; hM4Di) or TRPV1 ${ }^{\mathrm{Cre}}$ mice (Cre). CNO was repeatedly injected intraperitoneally $(40 \mu \mathrm{g} / 20 \mu \mathrm{l})$, to ipsilateral (ipsi; $20 \mu \mathrm{g} / 10 \mu \mathrm{l}$ ) or contralateral (contra; $20 \mu \mathrm{g} / 10 \mu \mathrm{l}$ ) V2 skin or intra-Vc (Vc; $0.1 \mu \mathrm{g} / 1 \mu \mathrm{l}$ ) at indicated time points. Mechanical sensitivity is presented as EF50 (the mechanical force that produced a 50\% response frequency) in the ipsilateral V2 skin; $* p<0.05, * * p<0.01, * * * p<0.001$ in Bonferroni post hoc test following two-way ANOVA. Throughout the figures, numbers in parenthesis represent the number of mice in each group. $\boldsymbol{B}$. Preconditioning habituation started at four to five weeks after $\mathrm{CCl}$ or sham surgery. Following the habituation period, the mice received intra-Vc microinjection of vehicle $(0.5-\mu l$ saline) in the ipsilateral side and paired with a chamber for $30 \mathrm{~min}$. Four hours later, the same mouse received $0.5-\mu \mathrm{CNO}$ paired with the other conditioning chamber for $30 \mathrm{~min}$. On the following test day, the mice were placed in the CPP chambers with free access to all chambers to measure time spent in both chambers. Mice were recorded for $15 \mathrm{~min}$, and difference scores were calculated by subtracting time spent in CNO-paired chambers before conditioning from the time after conditioning; $* p<0.05, * * p<0.01$ in Bonferroni post hoc test following two-way ANOVA. C, The effects of AMG9810 (100 nmol/10 $\mu \mathrm{l})$, a TRPV1 antagonist, or vehicle injected into the ipsilateral V2 skin on mechanical sensitivity in the ipsilateral V2 skin of mice with ION-CCI.

the hypothesis that TRPV1+ afferents contribute to the maintenance of TNP.

We previously showed that pharmacological inhibition of TRPV1 in central terminals within the Vc attenuates mechanical hyperalgesia in mice with ION-CCI (Kim et al., 2014). However, injection of AMG9810, an antagonist of TRPV1, into ipsilateral skin did not affect mechanical hyperalgesia (Fig. 1C), suggesting that TRPV1 plays different roles at peripheral and central terminals. Together, these results indicate that peripheral TRPV1+ afferents but not TRPV1 channels expressed in its peripheral terminals contribute to the maintenance of mechanical hyperalgesia after trigeminal nerve injury.

\section{Capsaicin-induced long-lasting analgesia in mice with CCI-ION}

To further test the hypothesis that capsaicin-induced ablation of TRPV1+ peripheral terminals produces analgesia, we conducted focal application of capsaicin to determine the effects of specific targeting TRPV1+ afferents. After the full establishment of mechanical hyperalgesia two weeks after the unilateral ION-CCI, we injected capsaicin $(10 \mu \mathrm{g})$ into maxillary V2 skin by subcutaneous injection under anesthesia. Then, mechanical sensitivity was tested at indicated time points after injection. The mice with ION-CCl exhibited a significant increase in mechanical threshold in V2 skin from $1 \mathrm{~d}$ (Fig. $2 A)$. Capsaicin injection did not produce any significant changes of the mechanical threshold in the sham group. However, a single injection of capsaicin in mice with ION$\mathrm{CCl}$ resulted in prolonged elevation of mechanical threshold from $1 \mathrm{~d}$ through $14 \mathrm{~d}$ compared with the vehicle group (drug, $F_{(1,151)}=45.47, p<0.0001$; time, $F_{(5,151)}$, $p=0.0021$; interaction, $F_{(5,151)}=3.15, p=0.0099$; twoway RM ANOVA). At $28 \mathrm{~d}$, mechanical threshold was still elevated compared with the vehicle group but did not reach statistical significance. Capsaicin injection did not affect mechanical sensitivity of ipsilateral skin in the sham group. We further examined whether capsaicin treatment in V2 skin also changes hypersensitivity in V3 skin. Interestingly, we found that capsaicin injection confined only to V2 skin also attenuated mechanical hyperalgesia in V3 skin (Fig. 2B). When percent responses to two VF filaments were compared (Fig. 2C,D), the effects of capsaicin were more pronounced. VF filaments exerting $0.39 \mathrm{~g}$ produced withdrawal responses $\sim 60 \%$ of the time whereas VF filaments exerting $0.81 \mathrm{~g}$ did so almost $100 \%$ time in ION-CCI group. After injection of capsaicin, there were substantially no responses to VF-0.39 g, whereas responses to VF- $0.81 \mathrm{~g}$ only occurred $\sim 50 \%$ of the time. $\mathrm{ION}-\mathrm{CCl}$ did not produce mechanical hyperalgesia in the contralateral skin, and capsaicin injection into the ipsilateral skin did not affect mechanical sensitivity in the contralateral skin (data not shown).

\section{Capsaicin injection attenuates pain aversion in mice with $\mathrm{CCI}-\mathrm{ION}$}

We next evaluated the effect of capsaicin on affective or aversive pain using a CPP paradigm (Fig. 3A). At two weeks after ION-CCl or sham surgery, mice received vehicle or capsaicin injection into the ipsilateral V2 skin. Two weeks after capsaicin or vehicle injection, we conditioned the mice using intra-Vc injection of lidocaine or vehicle. Comparing time spent in the lidocaine-paired chamber, there was a significant interaction between time and treatment groups $\left(F_{(3,41)}=9.76, p<0.0001\right.$; two-way $\mathrm{RM}$ ANOVA). Mice with ION-CCl receiving vehicle to $\mathrm{V} 2$ skin (CCl/Veh) spent a significantly longer time in the lidocaine-paired chamber on the testing day than on the preconditioning day, indicating analgesic effects of intra-Vc 
A

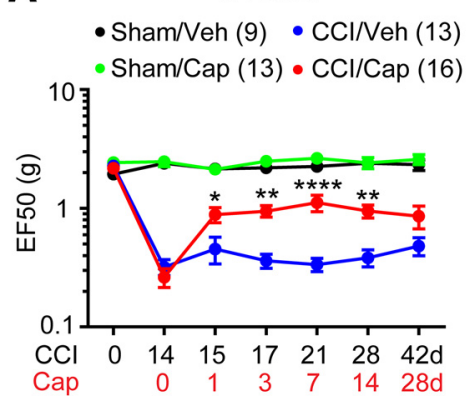

C VF $3.61(0.39 \mathrm{~g})$

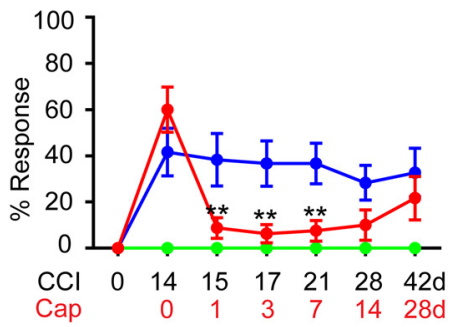

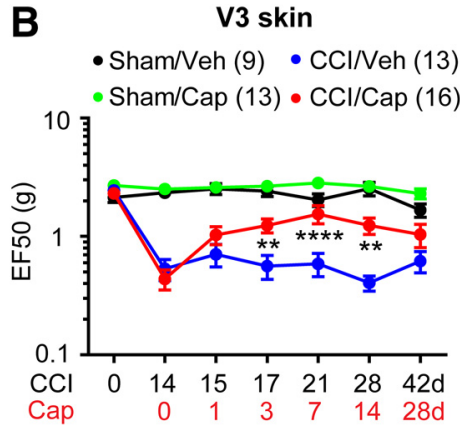

D VF $4.08(0.81 \mathrm{~g})$

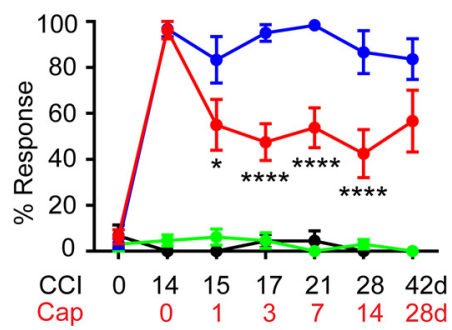

Figure 2. Single subcutaneous injection of capsaicin attenuates mechanical hyperalgesia in mice with $\mathrm{ION}-\mathrm{CCl}$. $\boldsymbol{A}, \boldsymbol{B}, \mathrm{Mechanical}$ sensitivity in the ipsilateral V2 skin $(\boldsymbol{A})$ or in the ipsilateral V3 skin $(\boldsymbol{B})$. Vehicle or capsaicin $(10 \mu \mathrm{g})$ was subcutaneously injected into the ipsilateral V2 skin area $14 \mathrm{~d}$ after $\mathrm{CCl}$ or sham surgery. $\boldsymbol{C}, \boldsymbol{D}$, Percent response frequency in response to VF hair $3.61(\boldsymbol{C})$ or 4.08 (D). Symbols and n numbers within parenthesis in $\boldsymbol{A}, \boldsymbol{B}$ are also applied to $\boldsymbol{C}, \boldsymbol{D}$. Two-way ANOVA followed by Bonferroni post hoc test (CCl/Veh vs CCl/Cap); $* p<0.05, * * p<0.01$, ****p $<0.0001$

A

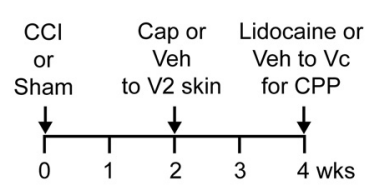

B

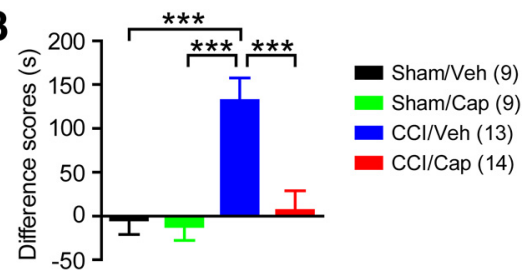

Figure 3. CPP test following capsaicin or vehicle injection in mice with CCI-ION or sham surgery. $\boldsymbol{A}$, Time course of CPP experiment. Preconditioning habituation started at four weeks after $\mathrm{CCl}$ or sham surgery (two weeks after cap or vehicle injection). Time spent in two chambers were recorded for $15 \mathrm{~min}$ (preconditioning trial). Following the habituation period, the mice received intra-Vc microinjection of vehicle $(0.5-\mu \mathrm{l}$ saline) in the ipsilateral side and paired with a chamber for 30 min. Four hours later, the same mouse received $0.5-\mu \mathrm{l} 2 \%$ lidocaine paired with the other conditioning chamber for $30 \mathrm{~min}$. On the following test day, the mice were placed in the CPP chambers with free access to all chambers to measure time spent in both chambers (testing trial). Mice were recorded for $15 \mathrm{~min}$, and chamber preference in comparison with preconditioning time was analyzed. $\boldsymbol{B}$, Difference scores were calculated by subtracting time spent in lidocaine-paired chambers during preconditioning trial from the time during testing trial; $* * * p<0.001$ in Bonferroni post hoc test following one-way ANOVA.

lidocaine on ongoing pain (preconditioning, $331 \pm 27 \mathrm{~s}$; testing, $462 \pm 34 \mathrm{~s} ; n=13 ; p<0.0001$ in Bonferroni post hoc test following two-way ANOVA). In contrast, ION$\mathrm{CCl}$ mice with capsaicin injection (CCl/Cap) spent almost equal amounts of time in lidocaine-paired chambers before and after the conditioning, indicating a lack of analgesia induced by lidocaine (preconditioning, $336 \pm 39 \mathrm{~s}$; testing, $343 \pm 36 \mathrm{~s} ; n=14 ; p>0.99)$. When difference scores were calculated (Fig. $3 B$ ), the CCl/ Veh group showed significantly greater scores than sham groups and CCl/Cap groups $\left(F_{(3,41)}=9.76\right.$, $p<0.0001$ in one-way ANOVA). The CCl/Cap group did not show a significant difference compared with sham groups. Overall, these results provide evidence that focally injected capsaicin leads to attenuation of ongoing affective pain

\section{Capsaicin-induced ablation of TRPV1 + peripheral terminals correlates with analgesia}

Injection of capsaicin into V2 skin contralateral to ION$\mathrm{CCl}$ did not affect mechanical sensitivity in either the ipsilateral side or the contralateral side, which supports that the effects of capsaicin are mediated by mechanisms localized to the ipsilateral skin (Fig. $4 A$ ). In our model, after capsaicin injection, mechanical threshold was not affected at $6 \mathrm{~h}$, whereas it was significantly attenuated at $1 \mathrm{~d}$ in mice with ION-CCI (Fig. 4B). In mice with sham 
A $\bigcirc$ Veh/Cont (9) $\bigcirc$ Cap/Cont (9)
- Veh/lpsi (9) $\odot$ Cap/lpsi (9)

年 $\mathrm{ION}-\mathrm{CCl}$

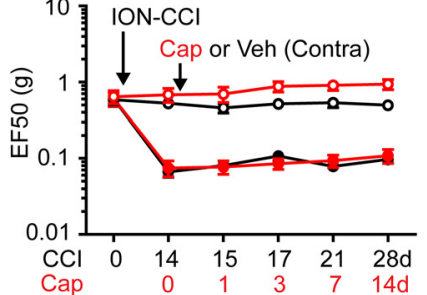

B

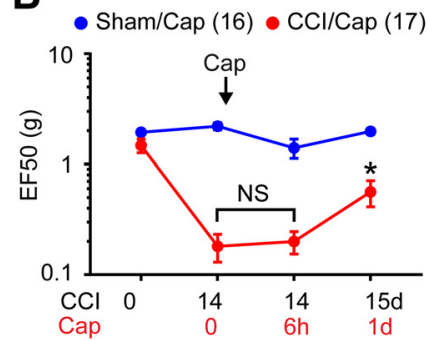

C

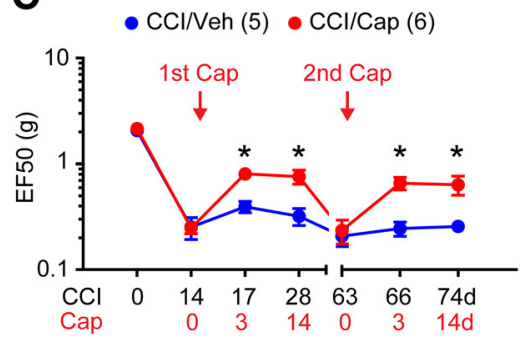

Figure 4. Properties of capsaicin-induced analgesia. $\boldsymbol{A}$, In mice with ION-CCI on the left side, the effects of capsaicin (red) or vehicle (black) injection into V2 skin on the right contralateral side. Mechanical sensitivity was measured from V2 skin in the contralateral side (open circles; capsaicin-injected right side) and ipsilateral side (filled circles; left side with ION-CCI). B, The effects of capsaicin injection into the ipsilateral V2 skin on mechanical sensitivity in the ipsilateral V2 skin of mice with ION-CCl (red) or sham (blue) at indicated time points. Capsaicin-induced analgesia was not initiated at $6 \mathrm{~h}$ following capsaicin injection. One-way RM ANOVA followed by Sidak multiple comparison test; $* p<0.05$ (vs Cap $0 \mathrm{~d}$ in $\mathrm{CCl} / \mathrm{Cap}$ group), NS, not significant. $\boldsymbol{C}$, The effects of repeated injection of capsaicin into the ipsilateral V2 skin on mechanical sensitivity in the ipsilateral V2 skin of mice with ION-CCl at indicated time points. Analgesia by first capsaicin disappeared after seven weeks following injection. Second capsaicin produced analgesia again; $* p<0.05$ (vs CCI/Veh group in each time point) in post hoc test following two-way RM ANOVA.
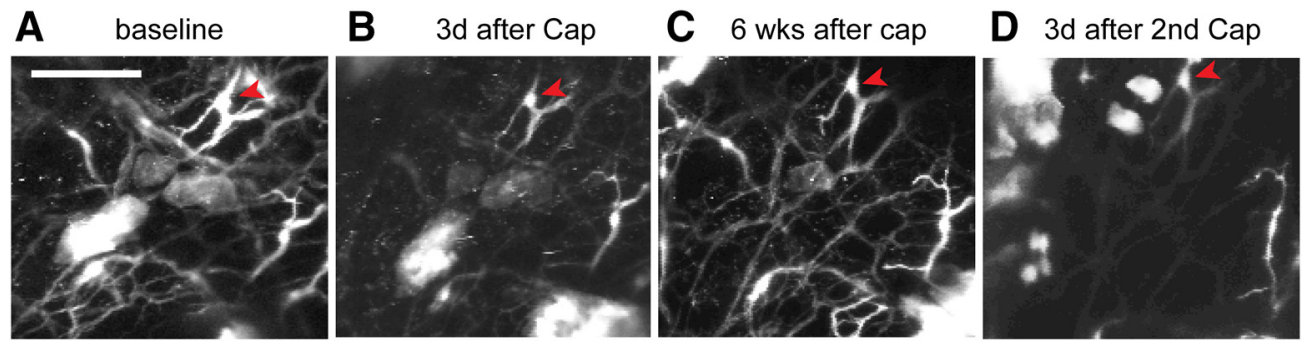

Figure 5. Capsaicin-induced ablation of TRPV1-LN afferent terminals is reversible and repeatable. Longitudinal monitoring of tdTomato + afferent terminals in intact hindpaw skin of a mouse expressing tdTomato from the locus of TRPV1 (TRPV1 ${ }^{\text {tdTomato }}$ ) using two-photon microscopy. To monitor capsaicin-mediated changes of tdTomato + afferent terminals, the same site was imaged repeatedly before $(\boldsymbol{A})$ and $3 \mathrm{~d}$ after first intraplantar injection of capsaicin $(10 \mu \mathrm{g} ; \boldsymbol{B})$. Six weeks after first injection of capsaicin $(\boldsymbol{C})$, the fibers were regenerated. Second injection of capsaicin reproduced ablation of the fibers $(\boldsymbol{D})$. Projected image stacks across $\sim 680 \mu \mathrm{m}(340 z$-axis sections at $2 \mu \mathrm{m})$. Scale bar: $100 \mu \mathrm{m}$.

surgery, capsaicin injection produced a modest decrease in mechanical threshold at $6 \mathrm{~h}$, which was not statistically significant $(p=0.16)$. In the clinic, capsaicin-induced analgesia is not permanent. Likewise, capsaicin-induced analgesia for mechanical hyperalgesia in the setting of ION$\mathrm{CCl}$ was extinguished by approximately seven weeks (Fig. $4 C)$. Following complete reacquisition of mechanical hyperalgesia, a second administration of capsaicin again produced similar analgesia (Fig. 4C, second Cap).

To evaluate reversible and repeatable ablation of cutaneous afferents, we performed longitudinal in vivo twophoton microscopy imaging to monitor TRPV1-LN nerve terminals in intact hindpaw skin of a TRPV ${ }^{\text {tdTomato }}$ mouse (Fig. 5). We longitudinally acquired images from the same skin site on multiple days. We found that intraplantar capsaicin treatment caused a reduction in the number of tdTomato + nerve terminals after $3 \mathrm{~d}$ (Fig. $5 A, B$ ). Ablation occurred in a majority of tdTomato + fibers, but some fibers were resistant to capsaicin (Fig. 5, arrowheads). This is likely due to the lack of TRPV1 expression in a subpopulation of TRPV1-LN neurons (Cavanaugh et al., 2011). The unaffected terminals served as a reference to facilitate longitudinal monitoring of the same site. When we checked the same site sixweeks following capsaicin injection, the number of tdTomato + fibers had recovered to a value similar to that at baseline (Fig. $5 C$ ), which was consistent with our findings in an immunohistochemical assay (Wang et al., 2017b). A second intraplantar injection of capsaicin produced ablation again (Fig. 5D). Overall, these results support that attenuation of mechanical hyperalgesia by capsaicin is correlated with ablation of afferent terminals in skin and that such ablation and attenuation can be conducted more than once.

\section{Capsaicin-induced ablation of TRPV1 + axonal terminals is necessary for capsaicin-induced analgesia}

To determine the role of the $\mathrm{Ca}^{2+} /$ calpain pathway in capsaicin-induced analgesia, we tested the effects of calpain inhibition on capsaicin-induced analgesia by co-administration of MDL28170 and capsaicin. Administration of capsaicin to V2 skin robustly attenuated mechanical hyperalgesia both in V2 and V3 in mice with $\mathrm{ION}-\mathrm{CCl}$ but not in sham mice (Fig. $6 A, B$ ), which is consistent with the results in Figure 2. In contrast, co-administration of capsaicin with MDL28170 did not increase mechanical threshold and substantially prevented capsaicin-induced 


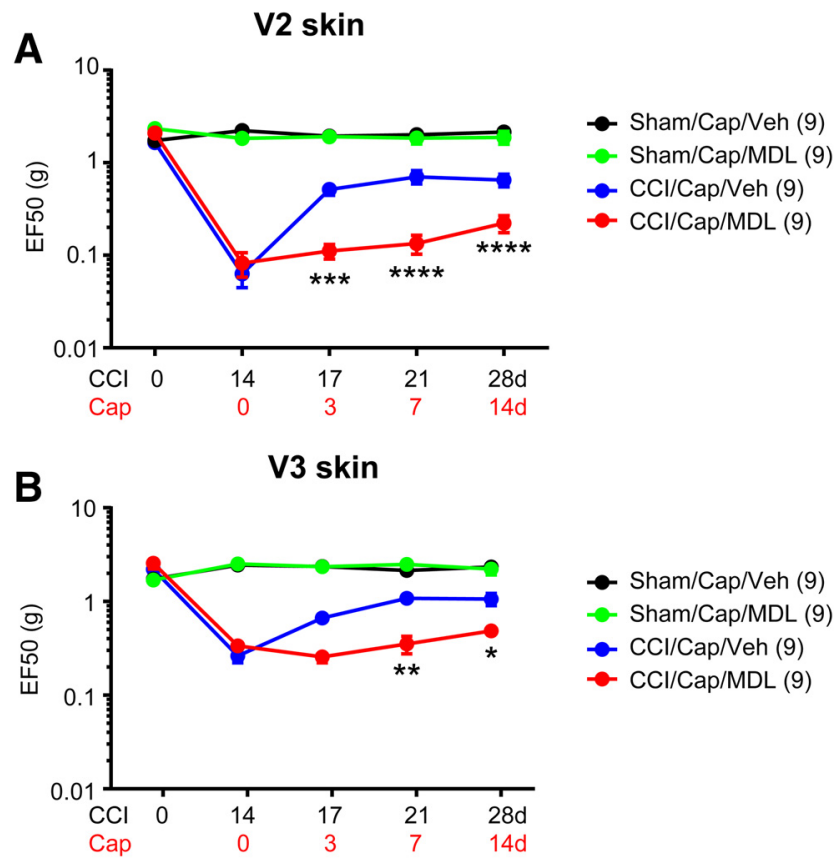

Figure 6. Inhibition of calpain attenuates capsaicin-induced analgesia for TNP. Mechanical hyperalgesia in V2 $(\boldsymbol{A})$ or V3 $(\boldsymbol{B})$ skin following $\mathrm{ION}-\mathrm{CCl}$ was attenuated by injection of capsaicin (Cap; $10 \mu \mathrm{g}$; blue). Co-administration of capsaicin with calpain inhibitor MDL28170 (MD; $10 \mu \mathrm{M}$ in $20 \mu \mathrm{l}$ ) into whisker pad area abolished capsaicin-induced analgesia for TNP compared with the injection of vehicle (Veh). Two-way RM ANOVA followed by Bonferroni post hoc test (CCl/Cap/Veh vs CCl/Cap/MDL); $* p<0.05, * * p<0.01, * * * p<0.0005, * * * * p<0.0001$.

analgesia both in V2 and V3 (interaction, $F_{(3,48)}=14.11$, $p<0.0001$; two-way RM ANOVA). The inhibitory effects of MDL28170 on capsaicin-induced ablation of afferent terminals were assessed through longitudinal imaging of cutaneous afferent terminals in hindpaw of TRPV1 ${ }^{\text {mGFP }}$ mice (Fig. 7). Using two-photon microscopy, GFP+ nerve terminals were captured from identical sites before and $3 \mathrm{~d}$ after the injection of capsaicin+vehicle (Cap+Veh) or capsaicin+MDL28170 (Cap+MDL) to the hindpaw (Fig. $7 A)$. For quantification, the proportion of GFP + pixels in entire ROI was calculated in each field of view (Fig. 7B). In baseline before injection, $\sim 15 \%$ of area was GFP + in both groups. Compared with the TRPV1 ${ }^{\text {tdTomato }}$ mice (Fig. 5), TRPV $1^{\text {mGFP }}$ mice exhibited networks of fine cutaneous afferent terminals more clearly. In 10 mice, we injected Cap+Veh or Cap+MDL to both hindpaws of five mice in each group. Three days after injection, we identified the same site by using the pattern of unaffected GFP + afferents as a reference. We were not able to locate the identical site in three hindpaws in each group, which were excluded from the analysis. In the Cap+Veh group, overall GFP+ signals were substantially reduced; fine GFP+ fibers disappeared and the brightness of GFP in large bundles of fibers were reduced, both of which were interpreted as consequence of the ablation by capsaicin. By contrast, GFP+ signals in the Cap+MDL group were comparable to those in baseline. When we quantified the GFP signals by measuring the proportion of GFP + pixels, the Cap+Veh group and the Cap+MDL showed significant different changes from baseline (interaction, $F_{(1,12)}=$ 9.19, $p=0.01$; two-way RM ANOVA). In post hoc analysis, the Cap+Veh group showed significantly less GFP+ pixels than Cap+MDL, indicating protective role of MDL28170 for capsaicin-induced ablation. These results suggest that TRPV $1 / \mathrm{Ca}^{2+} /$ calpain-dependent signaling plays a dominant role in capsaicin-induced analgesia for TNP and that capsaicin-induced ablation of afferent terminals is necessary for capsaicin-induced analgesia.

\section{Discussion}

Capsaicin has been widely used as a tool for reliably producing pain in both clinical and preclinical studies, which is mediated by the activation of TRPV1 in nociceptive afferent terminals (Caterina et al., 2000). Although capsaicin also has long been used as a therapeutic tool to attenuate chronic pain conditions (Chung and Campbell, 2016), mechanisms underlying capsaicin-induced analgesia has been enigmatic for centuries. In this study, we showed that a single focal injection of capsaicin induces long-lasting analgesic effects on both mechanical hyperalgesia and pain aversion in ION-CCI, a clinically relevant neuropathic pain model. We also showed that capsaicininduced ablation of TRPV1+ nociceptor terminals is closely correlated with capsaicin-induced analgesia: Time course of initiation of capsaicin-induced analgesia (1 d) is correlated with the time course of achieving full ablation of TRPV1+ afferents terminals after capsaicin injection (Wang et al., 2017b). Time course of extinction of capsaicin-induced analgesia (approximately seven weeks) is also correlated with the time required for epidermal nerve fiber regeneration following ablation (Wang et al., 2017b). A second application of capsaicin also produced ablation of nerve terminals and analgesia, which is reminiscent of the analgesia achieved by repeated application of topical capsaicin as is done in the clinic (Mou et al., 2013). Furthermore, capsaicin-induced analgesia was effectively abolished by co-administration of capsaicin and MDL28170. Based on the effects of MDL28170 preventing capsaicin-induced ablation of afferent terminals (Fig. 7; Wang et al., 2017b), we concluded that the effects of MDL28170 on capsaicin-induced analgesia are likely mediated by the prevention of capsaicin-induced ablation of TRPV1+ afferent terminals. Because of the technical difficulty of quantifying afferent terminals in hairy skin, we were not able to directly determine the association of capsaicin-induced ablation of afferent terminals in facial skin with analgesia. Despite this limitation, our data strongly support our hypothesis that capsaicin-induced ablation of peripheral nociceptive fibers is necessary for capsaicininduced analgesia.

Capsaicin administration can cause desensitization of TRPV1 (Joseph et al., 2013), inhibition of nociceptor firing (Ma et al., 2015), or decrease in mechanotransduction (Borbiro et al., 2015). Such early effects of capsaicin on the function of primary afferents might potentially contribute to analgesic effects immediately after capsaicin injection. However, we do not think these early events contributed to the long-lasting analgesia observed in this 

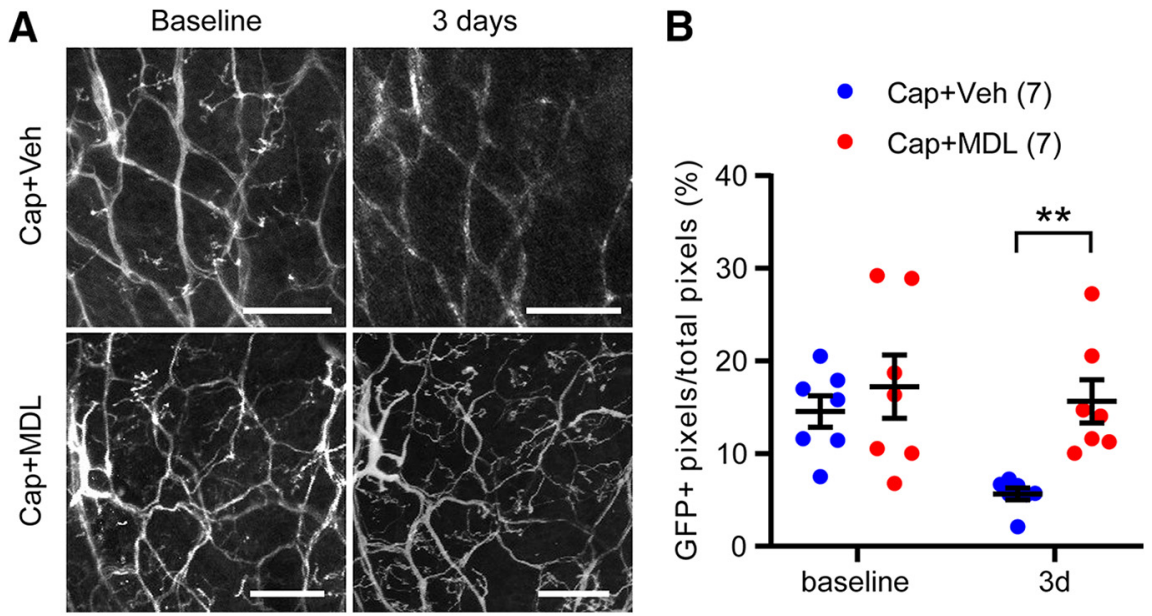

Figure 7. Inhibition of calpain attenuates capsaicin-induced ablation of TRPV1-LN afferent terminals in hindpaw. $\boldsymbol{A}$, Longitudinal in vivo two-photon imaging of GFP + afferent terminals in intact hindpaw of a mouse expressing mGFP from the locus of TRPV1 (TRPV1 ${ }^{\text {mGFP }}$ ). To assess changes of GFP+ afferent terminals, the same site was imaged repeatedly before (baseline) and $3 \mathrm{~d}$ after intraplantar injection of vehicle or MDL28170 (10 $\mu \mathrm{M}$ in $10 \mu \mathrm{l})$ followed by capsaicin $(10 \mu \mathrm{g})$. The images represent projected image stacks across $100-150 \mu \mathrm{m}(200-300 z$-axis sections at $0.5 \mu \mathrm{m})$. Scale bar: $50 \mu \mathrm{m}$. $\boldsymbol{B}$, In each stacked image, the proportion of GFP+ pixels/total pixels in the imaged area was calculated. $N=7$ hindpaws from 5 mice per group; $* * p<0.01$ in Sidak post hoc assay following two-way ANOVA.

study, since capsaicin-induced analgesia was evident at $1 \mathrm{~d}$ after injection but not at $6 \mathrm{~h}$. Capsaicin administration could also produce analgesia through diffuse noxious inhibitory control (DNIC; Da Silva et al., 2018). It is unlikely, however, that such DNIC effects contribute to the longlasting analgesia, since the time course of DNIC is transient ( 30 min; Da Silva et al., 2018) and capsaicin-induced DNIC is lost following neuropathic injury (Phelps et al., 2019).

The amount of capsaicin used in this study is $<1 \%$ of the dose required for systemic ablation of afferents (Jancsó et al., 1985). Consistently, injection of capsaicin to the contralateral skin did not produce analgesia on the ipsilateral side, providing evidence that capsaicin exerts its effects locally. Although the extent of ablation of afferent soma in sensory ganglia following subcutaneous injection of capsaicin has not been precisely determined, the proportions of TRPV1-LN neurons in sensory ganglia were not affected by intraplantar capsaicin injection (Wang et al., 2017b), which is also consistent with localized effects (Karai et al., 2004; Yu and Premkumar, 2015). Along with the correlation between capsaicin-induced hypoalgesia and the ablation of afferent terminals in humans (Simone et al., 1998; Polydefkis et al., 2004; Ragé et al., 2010), our results suggest that capsaicin-induced localized ablation of TRPV1 + terminals is the primary determinant of capsaicin-induced analgesia.

TRPV1+ afferents and TRPV1-LN afferents do not function as mechanosensitive neurons under physiological conditions: ablation of TRPV1-LN neurons in mice eliminates heat and cold responses, but basal mechanical sensitivity is not affected (Mishra et al., 2011). Chemical ablation of TRPV1 + afferents does not affect mechanical sensitivity (Karai et al., 2004). Our previous study in the TRPV $1^{\mathrm{hM} 4 \mathrm{Di}}$ mice also indicated that basal thermal and mechanical nociceptive threshold as well as the development of inflammatory pain were unaffected compared with TRPV1 ${ }^{\text {Cre }}$ control mice (Wang et al., 2017a). Consistently, mechanical sensitivity in sham animals were not affected by chemogenetic silencing of TRPV1-LN afferents by CNO. However, chemogenetic inhibition of TRPV1-LN afferent terminals in mice with $\mathrm{ION}-\mathrm{CCl}$ attenuated mechanical hyperalgesia, which further support the necessity of TRPV1 + afferent terminals in mechanical hyperalgesia under pathologic conditions. Of note, since TRPV1-LN afferents contain TRPV1-negative afferents (Cavanaugh et al., 2011) and TRPV1-negative TRPV1-LN neurons are mostly non-peptidergic A $\delta$ or c-nociceptors (Patil et al., 2018), we cannot exclude the possibility that TRPV1-negative nociceptors could have contributed in the chemogenetic study. Further investigation of neuroplasticity of trigeminal afferents in TRPV1-LN, including non-peptidergic nociceptors, is warranted.

How do TRPV1 + afferents contribute to mechanical hyperalgesia after ION-CCI? Peripheral neuropathy is known to produce a wide variety of changes in TRPV1 expression in sensory ganglia (Hudson et al., 2001; Fukuoka et al., 2002; Kanai et al., 2005; Biggs et al., 2007; Christoph et al., 2007; Kim et al., 2008; Vilceanu et al., 2010; Urano et al., 2012; Hirai et al., 2014). Sensitization of TRPV1 in central terminals within the Vc contributes to synaptic facilitation of primary afferent excitatory input and maintains mechanical hyperalgesia following ION$\mathrm{CCl}$ in mice (Kim et al., 2014). ION-CCl enhances overall capsaicin responses of TG neurons including some larger diameter TG neurons (Kim et al., 2014). These functional changes are consistent with the TRPV1 upregulation in larger diameter myelinated afferents reported in other trigeminal neuropathy models (Kim et al., 2008; Urano et al., 2012; Zakir et al., 2012). Peripheral nerve axotomy also induces de novo expression of TRPV1 in isolectin B4+ afferents (Vilceanu et al., 2010; Wang et al., 2011), a subset 
of mechanosensitive afferents (Cavanaugh et al., 2009). Therefore, ION-CCI possibly induces de novo expression of TRPV1 in mechanosensitive afferents, e.g., IB4+ afferents, which could facilitate synaptic transmission of mechanical afferent information in the central terminals to maintain mechanical hyperalgesia. Certainly, our data (Fig. 1C) suggest that TRPV1 molecule itself at the peripheral terminals is not responsible for transducing mechanical pain in ION-CCl. However, de novo expression of TRPV1 in mechanosensitive afferents after ION-CCI should render sensitivity to administered capsaicin to the peripheral terminals of these afferents, and focal capsaicin could thereby produce ablation and concomitant analgesia for mechanical hyperalgesia under ION-CCI. Any such causal contributions of neuroplastic changes of TRPV1 in distinct subsets of trigeminal afferents to hyperalgesia following ION-CCI need to be determined in future studies.

It is highly likely that capsaicin-induced ablation of nerve terminals is necessary but not sufficient to explain the full spectrum of analgesic effects of this compound and that these effects also involve supraspinal mechanisms. For example, since capsaicin-induced analgesia occurs in extraterritorial V3 skin and the secondary mechanical hyperalgesia in V3 is driven by central terminal TRPV1 sensitization (Kim et al., 2014) and descending facilitation from the rostral ventromedial medulla (Okubo et al., 2013), peripheral capsaicin injection may produce analgesia over a broad orofacial area through the normalization of descending pain facilitation after long-term attenuation of nociceptive input from injured nerves. In addition to analgesia to evoked pain, capsaicin injection also attenuates aversive features of neuropathic pain as assessed by CPP. This suggests the effects of capsaicininduced ablation on brain structures involved in affective pain. We do not anticipate direct actions of capsaicin on the brain. Rather, capsaicin-induced ablation of nociceptive afferent terminals and consequent prolonged reduction of nociceptive inputs into the brain likely result in altered pain processing, e.g., reduced central sensitization, in regions subserving sensory-discriminative and affective components of pain. Indeed, lidocaine patch treatment attenuates spontaneous pain from postherpetic neuralgia, which is accompanied by attenuation of increased activity of pain-related brain regions (Geha et al., 2007). It will be necessary to define the plastic changes in sensory and affective pain pathways associated with capsaicin-induced analgesia in the future.

Given the paucity of data supporting the contribution of TRPV1+ afferents to hyperalgesia in spinal neuropathic pain models (Ossipov et al., 1999; King et al., 2011; Mishra et al., 2011; Abooj et al., 2016), our results in the ION-CCI model are surprising. Diverse pathophysiological mechanisms among the variety of commonly used peripheral neuropathy models might contribute to the discrepancy. Presumably TRPV1+ afferents could contribute to mechanical hyperalgesia in cases when nociceptors are relatively intact and abnormally sensitized. In our model, we used chromic gut for loose ligation of ION. Although this model does not involve substantial deafferentation, it is accompanied by strong inflammatory components due to chromic gut (Ma et al., 2012) and likely involves a greater role of TRPV1+ nociceptors and, hence, a greater degree of capsaicin-induced analgesia. It is possible that ION-CCI mimics neuropathic pain in a certain population of patients who are more susceptible to topical capsaicin treatment. Indeed, capsaicin is not effective in every neuropathic pain patient but is only effective in less than half of patients treated (Backonja et al., 2008). Recent studies have shown that patients with neuropathic pain syndromes exhibit a wide spectrum of sensory symptoms (loss or gain in thermal and mechanical sensitivity), suggesting the involvement of diverse underlying central and peripheral mechanisms (Maier et al., 2010; Baron et al., 2017). In a study of $\sim 900$ peripheral neuropathy patients with diverse etiologies, unbiased clustering based on their sensory profiles revealed that $33 \%$ of patients formed a group showing significant sensory gain (without sensory loss; Baron et al., 2017). This group of patients showed heat and cold hyperalgesia as well as mechanical hyperalgesia (enhanced pressure and pinprick response; Baron et al., 2017). Such hyperalgesia may be mediated by intact but abnormally hyperactive primary afferent nociceptors ("irritable nociceptors"; Fields et al., 1998). These findings suggest that selectively targeting "irritable" nociceptors using capsaicin might improve pain management in this group of patients. Considering the fact that topical capsaicin was shown to be effective in alleviating TNP in humans (Epstein and Marcoe, 1994; Pastre et al., 2008; Wagner et al., 2013), our data using the ION-CCI model likely suggest that TRPV1 or TRPV1 + afferents are effective targets for treating TNP.

In conclusion, we showed that local chemogenetic silencing of peripheral TRPV1-LN afferents reduces mechanical hyperalgesia after trigeminal nerve injury. Strikingly, we further found that a single focal injection of capsaicin induces longlasting analgesia. Capsaicin-induced analgesia is closely correlated with capsaicin-induced ablation of TRPV1+ nociceptor fibers, which supports our hypothesis that TRPV1+ afferents contribute to the maintenance of TNP and capsaicin-induced ablation of peripheral nociceptive fibers is necessary for capsaicin-induced analgesia. These results strongly suggest that TRPV1+ afferents contribute to the maintenance of TNP and their targeting could be therapeutic for treating TNP in the clinic. Further elucidation of the mechanisms underlying capsaicin-induced analgesia should facilitate improve capsaicin therapy by reducing the associated procedural pain and enhancing therapeutic efficacy.

\section{References}

Abooj M, Bishnoi M, Bosgraaf CA, Premkumar LS (2016) Changes in spinal cord following inflammatory and neuropathic pain and the effectiveness of resiniferatoxin. Open Pain J 9:1-4.

Agbaje JO, Van de Casteele E, Hiel M, Verbaanderd C, Lambrichts I, Politis C (2016) Neuropathy of trigeminal nerve branches after oral and maxillofacial treatment. J Maxillofac Oral Surg 15:321-327.

Anand P, Bley K (2011) Topical capsaicin for pain management: therapeutic potential and mechanisms of action of the new high-concentration capsaicin 8\% patch. Br J Anaesth 107:490-502.

Backonja M, Wallace MS, Blonsky ER, Cutler BJ, Malan P Jr, Rauck R, Tobias J; NGX-4010 C116 Study Group (2008) NGX-4010, a high-concentration capsaicin patch, for the treatment of 
postherpetic neuralgia: a randomised, double-blind study. Lancet Neurol 7:1106-1112.

Baron R, Maier C, Attal N, Binder A, Bouhassira D, Cruccu G, Finnerup NB, Haanpää $M$, Hansson $P$, Hüllemann $P$, Jensen TS, Freynhagen R, Kennedy JD, Magerl W, Mainka T, Reimer M, Rice ASC, Segerdahl M, Serra J, Sindrup S, et al. (2017) Peripheral neuropathic pain: a mechanism-related organizing principle based on sensory profiles. Pain 158:261-272.

Biggs JE, Yates JM, Loescher AR, Clayton NM, Boissonade FM, Robinson PP (2007) Changes in vanilloid receptor 1 (TRPV1) expression following lingual nerve injury. Eur J Pain 11:192-201.

Borbiro I, Badheka D, Rohacs T (2015) Activation of TRPV1 channels inhibits mechanosensitive Piezo channel activity by depleting membrane phosphoinositides. Sci Signal 8:ra15.

Caterina MJ, Leffler A, Malmberg AB, Martin WJ, Trafton J, Petersen-Zeitz KR, Koltzenburg M, Basbaum Al, Julius D (2000) Impaired nociception and pain sensation in mice lacking the capsaicin receptor. Science 288:306-313.

Cavanaugh DJ, Lee H, Lo L, Shields SD, Zylka MJ, Basbaum Al, Anderson DJ (2009) Distinct subsets of unmyelinated primary sensory fibers mediate behavioral responses to noxious thermal and mechanical stimuli. Proc Natl Acad Sci USA 106:9075-9080.

Cavanaugh DJ, Chesler AT, Jackson AC, Sigal YM, Yamanaka H, Grant R, O'Donnell D, Nicoll RA, Shah NM, Julius D, Basbaum AI (2011) Trpv1 reporter mice reveal highly restricted brain distribution and functional expression in arteriolar smooth muscle cells. $J$ Neurosci 31:5067-5077.

Christoph T, Gillen C, Mika J, Grünweller A, Schäfer MK, Schiene K, Frank R, Jostock R, Bahrenberg G, Weihe E, Erdmann VA, Kurreck $J$ (2007) Antinociceptive effect of antisense oligonucleotides against the vanilloid receptor VR1/TRPV1. Neurochem Int 50:281290.

Chung MK, Campbell JN (2016) Use of capsaicin to treat pain: mechanistic and therapeutic considerations. Pharmaceuticals (Basel) 9.

Chung MK, Jung SJ, Oh SB (2011) Role of TRP channels in pain sensation. Adv Exp Med Biol 704:615-636.

Cruccu G, Nurmikko TJ, Ernault E, Riaz FK, McBride WT, Haanpää M (2018) Superiority of capsaicin $8 \%$ patch versus oral pregabalin on dynamic mechanical allodynia in patients with peripheral neuropathic pain. Eur J Pain 22:700-706.

Da Silva JT, Zhang Y, Asgar J, Ro JY, Seminowicz DA (2018) Diffuse noxious inhibitory controls and brain networks are modulated in a testosterone-dependent manner in Sprague Dawley rats. Behav Brain Res 349:91-97.

Epstein JB, Marcoe JH (1994) Topical application of capsaicin for treatment of oral neuropathic pain and trigeminal neuralgia. Oral Surg Oral Med Oral Pathol 77:135-140.

Fields HL, Rowbotham M, Baron R (1998) Postherpetic neuralgia: irritable nociceptors and deafferentation. Neurobiol Dis 5:209-227.

Fukuoka T, Tokunaga A, Tachibana T, Dai Y, Yamanaka H, Noguchi K (2002) VR1, but not P2X(3), increases in the spared L4 DRG in rats with L5 spinal nerve ligation. Pain 99:111-120.

Geha PY, Baliki MN, Chialvo DR, Harden RN, Paice JA, Apkarian AV (2007) Brain activity for spontaneous pain of postherpetic neuralgia and its modulation by lidocaine patch therapy. Pain 128:88100.

Haviv Y, Zadik Y, Sharav Y, Benoliel R (2014) Painful traumatic trigeminal neuropathy: an open study on the pharmacotherapeutic response to stepped treatment. J Oral Facial Pain Headache 28:52-60.

Hirai T, Enomoto M, Kaburagi H, Sotome S, Yoshida-Tanaka K, Ukegawa M, Kuwahara $\mathrm{H}$, Yamamoto $M$, Tajiri M, Miyata $\mathrm{H}$, Hirai Y, Tominaga M, Shinomiya K, Mizusawa H, Okawa A, Yokota T (2014) Intrathecal AAV serotype 9-mediated delivery of shRNA against TRPV1 attenuates thermal hyperalgesia in a mouse model of peripheral nerve injury. Mol Ther 22:409-419.

Hudson LJ, Bevan S, Wotherspoon G, Gentry C, Fox A, Winter J (2001) VR1 protein expression increases in undamaged DRG neurons after partial nerve injury. Eur J Neurosci 13:2105-2114. ladarola MJ, Sapio MR, Raithel SJ, Mannes AJ, Brown DC (2018) Long-term pain relief in canine osteoarthritis by a single intra-articular injection of resiniferatoxin, a potent TRPV1 agonist. Pain 159:2105-2114.

Jancsó G, Király E, Joó F, Such G, Nagy A (1985) Selective degeneration by capsaicin of a subpopulation of primary sensory neurons in the adult rat. Neurosci Lett 59:209-214.

Joseph J, Wang S, Lee J, Ro JY, Chung MK (2013) Carboxyl-terminal domain of transient receptor potential vanilloid 1 contains distinct segments differentially involved in capsaicin- and heat-induced desensitization. J Biol Chem 288:35690-35702.

Kanai Y, Nakazato E, Fujiuchi A, Hara T, Imai A (2005) Involvement of an increased spinal TRPV1 sensitization through its up-regulation in mechanical allodynia of $\mathrm{CCl}$ rats. Neuropharmacology 49:977984.

Karai L, Brown DC, Mannes AJ, Connelly ST, Brown J, Gandal M, Wellisch OM, Neubert JK, Olah Z, ladarola MJ (2004) Deletion of vanilloid receptor 1-expressing primary afferent neurons for pain control. J Clin Invest 113:1344-1352.

Kennedy WR, Vanhove GF, Lu SP, Tobias J, Bley KR, Walk D, Wendelschafer-Crabb G, Simone DA, Selim MM (2010) A randomized, controlled, open-label study of the long-term effects of NGX4010, a high-concentration capsaicin patch, on epidermal nerve fiber density and sensory function in healthy volunteers. J Pain 11:579-587.

Kim HY, Park CK, Cho IH, Jung SJ, Kim JS, Oh SB (2008) Differential Changes in TRPV1 expression after trigeminal sensory nerve injury. J Pain 9:280-288.

Kim YS, Chu Y, Han L, Li M, Li Z, Lavinka PC, Sun S, Tang Z, Park K, Caterina MJ, Ren K, Dubner R, Wei F, Dong X (2014) Central terminal sensitization of TRPV1 by descending serotonergic facilitation modulates chronic pain. Neuron 81:873-887.

King T, Qu C, Okun A, Mercado R, Ren J, Brion T, Lai J, Porreca F (2011) Contribution of afferent pathways to nerve injury-induced spontaneous pain and evoked hypersensitivity. Pain 152:19972005.

Landowski LM, Dyck PJ, Engelstad J, Taylor BV (2016) Axonopathy in peripheral neuropathies: mechanisms and therapeutic approaches for regeneration. J Chem Neuroanat 76:19-27.

Ma F, Zhang L, Lyons D, Westlund KN (2012) Orofacial neuropathic pain mouse model induced by trigeminal inflammatory compression (TIC) of the infraorbital nerve. Mol Brain 5:44.

Ma XL, Zhang FX, Dong F, Bao L, Zhang X (2015) Experimental evidence for alleviating nociceptive hypersensitivity by single application of capsaicin. Mol Pain 11:22.

Maier C, Baron R, Tölle TR, Binder A, Birbaumer N, Birklein F, Gierthmühlen J, Flor H, Geber C, Huge V, Krumova EK, Landwehrmeyer GB, Magerl W, Maihöfner C, Richter H, Rolke R, Scherens A, Schwarz A, Sommer C, Tronnier V, et al. (2010) Quantitative sensory testing in the German Research Network on Neuropathic Pain (DFNS): somatosensory abnormalities in 1236 patients with different neuropathic pain syndromes. Pain 150:439450.

Malmberg AB, Mizisin AP, Calcutt NA, von Stein T, Robbins WR, Bley KR (2004) Reduced heat sensitivity and epidermal nerve fiber immunostaining following single applications of a high-concentration capsaicin patch. Pain 111:360-367.

McQuay HJ, Tramèr M, Nye BA, Carroll D, Wiffen PJ, Moore RA (1996) A systematic review of antidepressants in neuropathic pain. Pain 68:217-227.

Mishra SK, Tisel SM, Orestes P, Bhangoo SK, Hoon MA (2011) TRPV1-lineage neurons are required for thermal sensation. EMBO J 30:582-593.

Mou J, Paillard F, Turnbull B, Trudeau J, Stoker M, Katz NP (2013) Efficacy of Qutenza(R) (capsaicin) $8 \%$ patch for neuropathic pain: a meta-analysis of the Qutenza Clinical Trials Database. Pain 154:1632-1639.

Okubo M, Castro A, Guo W, Zou S, Ren K, Wei F, Keller A, Dubner R (2013) Transition to persistent orofacial pain after nerve injury 
involves supraspinal serotonin mechanisms. J Neurosci 33:51525161.

Ossipov MH, Bian D, Malan TP, Jr., Lai J, Porreca F (1999) Lack of involvement of capsaicin-sensitive primary afferents in nerve-ligation injury induced tactile allodynia in rats. Pain 79:127-133.

Pastre T, Faot F, Westphalen FH, da Rosa RS (2008) Treatment of painful post-traumatic peripheral neuropathy with capsaicin in an edentulous patient with extreme resorption in the mental region: a case report. J Contemp Dent Pract 9:106-113.

Patil MJ, Hovhannisyan AH, Akopian AN (2018) Characteristics of sensory neuronal groups in CGRP-cre-ER reporter mice: comparison to Nav1.8-cre, TRPV1-cre and TRPV1-GFP mouse lines. PLoS One 13:e0198601.

Paxinos G, Franklin KBJ (2008) The mouse brain in stereotaxic coordinates, Ed 3. Amsterdam; Boston: Elsevier Academic Press.

Phelps CE, Navratilova E, Dickenson AH, Porreca F, Bannister K (2019) Kappa opioid signaling in the right central amygdala causes hind paw specific loss of diffuse noxious inhibitory controls in experimental neuropathic pain. Pain 160:1614-1621.

Polydefkis M, Hauer P, Sheth S, Sirdofsky M, Griffin JW, McArthur JC (2004) The time course of epidermal nerve fibre regeneration: studies in normal controls and in people with diabetes, with and without neuropathy. Brain 127:1606-1615.

Pomonis JD, Harrison JE, Mark L, Bristol DR, Valenzano KJ, Walker K (2003) N-(4-Tertiarybutylphenyl)-4-(3-cholorphyridin-2-yl)tetrahydropyrazine $-1(2 \mathrm{H})$-carbox-amide (BCTC), a novel, orally effective vanilloid receptor 1 antagonist with analgesic properties: II. In vivo characterization in rat models of inflammatory and neuropathic pain. J Pharmacol Exp Ther 306:387-393.

Ragé M, Van Acker N, Facer P, Shenoy R, Knaapen MW, Timmers M, Streffer J, Anand P, Meert T, Plaghki L (2010) The time course of $\mathrm{CO} 2$ laser-evoked responses and of skin nerve fibre markers after topical capsaicin in human volunteers. Clin Neurophysiol 121:1256-1266.

Rashid $\mathrm{MH}$, Inoue M, Kondo S, Kawashima T, Bakoshi S, Ueda H (2003) Novel expression of vanilloid receptor 1 on capsaicin-insensitive fibers accounts for the analgesic effect of capsaicin cream in neuropathic pain. J Pharmacol Exp Ther 304:940-948.

Sapio MR, Neubert JK, LaPaglia DM, Maric D, Keller JM, Raithel SJ, Rohrs EL, Anderson EM, Butman JA, Caudle RM, Brown DC, Heiss JD, Mannes AJ, ladarola MJ (2018) Pain control through selective chemo-axotomy of centrally projecting TRPV1+ sensory neurons. J Clin Invest 128:1657-1670.

Simone DA, Nolano M, Johnson T, Wendelschafer-Crabb G, Kennedy WR (1998) Intradermal injection of capsaicin in humans produces degeneration and subsequent reinnervation of epidermal nerve fibers: correlation with sensory function. J Neurosci 18:8947-8959.

Stevens RM, Ervin J, Nezzer J, Nieves Y, Guedes K, Burges R, Hanson PD, Campbell JN (2019) Randomized, double-blind, placebo-controlled trial of intraarticular trans-capsaicin for pain associated with osteoarthritis of the knee. Arthritis Rheumatol 71:1524-1533.

Szallasi A, Blumberg PM (1999) Vanilloid (capsaicin) receptors and mechanisms. Pharmacol Rev 51:159-212.

Treede RD, Wagner T, Kern KU, Husstedt IW, Arendt G, Birklein F, Cegla T, Freynhagen R, Gockel HH, Heskamp ML, Jager $H$, Joppich R, Maier C, Leffler A, Nagelein HH, Rolke R, Seddigh S, Sommer C, Stander S, Wasner G, et al. (2013) Mechanism- and experience-based strategies to optimize treatment response to the capsaicin $8 \%$ cutaneous patch in patients with localized neuropathic pain. Curr Med Res Opin 29:527-538.

Urano H, Ara T, Fujinami Y, Hiraoka BY (2012) Aberrant TRPV1 expression in heat hyperalgesia associated with trigeminal neuropathic pain. Int J Med Sci 9:690-697.

Vilceanu D, Honore P, Hogan QH, Stucky CL (2010) Spinal nerve ligation in mouse upregulates TRPV1 heat function in injured IB4positive nociceptors. J Pain 11:588-599.

Wagner T, Poole C, Roth-Daniek A (2013) The capsaicin 8\% patch for neuropathic pain in clinical practice: a retrospective analysis. Pain Med 14:1202-1211.

Wang S, Lim J, Joseph J, Wang S, Wei F, Ro JY, Chung MK (2017a) Spontaneous and bite-evoked muscle pain are mediated by a common nociceptive pathway with differential contribution by TRPV1. J Pain 18:1333-1345.

Wang S, Wang S, Asgar J, Joseph J, Ro JY, Wei F, Campbell JN, Chung MK (2017b) Ca2 + and calpain mediate capsaicin-induced ablation of axonal terminals expressing transient receptor potential vanilloid 1. J Biol Chem 292:8291-8303.

Wang S, Brigoli B, Lim J, Karley A, Chung MK (2018) Roles of TRPV1 and TRPA1 in spontaneous pain from inflamed masseter muscle. Neuroscience 384:290-299.

Wang T, Molliver DC, Jing X, Schwartz ES, Yang FC, Samad OA, Ma Q, Davis BM (2011) Phenotypic switching of nonpeptidergic cutaneous sensory neurons following peripheral nerve injury. PLoS One 6:e28908.

Watabiki T, Kiso T, Kuramochi T, Yonezawa K, Tsuji N, Kohara A, Kakimoto S, Aoki T, Matsuoka N (2011) Amelioration of neuropathic pain by novel transient receptor potential vanilloid 1 antagonist AS1928370 in rats without hyperthermic effect. J Pharmacol Exp Ther 336:743-750.

Yu S, Premkumar LS (2015) Ablation and regeneration of peripheral and central TRPV1 expressing nerve terminals and the consequence of nociception. Open Pain J 8:1-9.

Zakir HM, Mostafeezur RM, Suzuki A, Hitomi S, Suzuki I, Maeda T, Seo K, Yamada Y, Yamamura K, Lev S, Binshtok AM, Iwata K, Kitagawa J (2012) Expression of TRPV1 channels after nerve injury provides an essential delivery tool for neuropathic pain attenuation. PLoS One 7:e44023.

Zis P, Apsokardos A, Isaia C, Sykioti P, Vadalouca A (2014) Posttraumatic and postsurgical neuropathic pain responsive to treatment with capsaicin $8 \%$ topical patch. Pain Physician 17: E213-E218. 